\title{
Structure of Congenital Heart Defects in Newborns in the Sakha Republic (Yakutia)
}

\author{
Tuyara I. Nelunova ${ }^{1}$, PGS; Vyacheslav G. Chasnyk ${ }^{1}, \mathrm{PhD}, \mathrm{ScD}$; \\ Tatiana E. Burtseva ${ }^{2}, \mathrm{PhD}$, ScD; Mikhail I.Tomsky², PhD, ScD; Evdokia D. Son ${ }^{3}, \mathrm{PhD}$ \\ ${ }^{1}$ Saint Petersburg Medical University, St. Petersburg, Russia \\ ${ }^{2}$ Yakutsk Research Center for Complex Medical Problems, Yakutsk, Sakha Republic, Russia \\ ${ }^{3}$ North-Eastern Federal University Ammosov, Yakutsk, Sakha Republic, Russia
}

\begin{abstract}
The results of a retrospective study of newly diagnosed cases of congenital heart defects (CHDs) among liveborn infants in the Sakha Republic (Yakutia, SR(Y)) are presented. The study was divided into two time periods: Period A (from 2002 to 2002) and Period B (from 2011 to 2013). A comparative analysis of the prevalence of CHD detection and the structure of clinical entities of CHDs among liveborn infants in Period A (42,827 liveborn infants and 186 cases of CHDs) and Period B (50,104 liveborn infants and 899 cases of CHDs) was performed. The prevalence of CHDs among newborns in Period A was 4.34 per 1,000 live births, which corresponded to the average CHD frequency in Russia. The prevalence of CHDs among newborns in Period B was 17.9 per 1,000 live births, which is significantly higher than in Period A $(P=0.0000)$. The overall growth of the incidence of CHDs among newborns in period B was due to an increase in the prevalence and frequency of septal defects. The increase in the prevalence of CHDs could be due to many factors, including improvement in the quality of diagnosis in 2011-2013.
\end{abstract}

Keywords: congenital heart defects; the Sakha Republic (Yakutia); quality of diagnosis.

\section{Introduction}

Currently, the congenital malformations (CDF congenital defect fetus) that occur in $4.0 \%$ to $6.0 \%$ of newborns play an important role in the structure of child morbidity, disability, and infant mortality; their contribution to the structure of a child's death in the first year of life is more than 20\% [1-3]. In CDF structure, CHDs and defects of the great vessels occupy one of the first places (22\% of all CDFs) and their prevalence at birth is 8 to 14 cases per 1,000 newborns in all countries [4]. Studies conducted in the USA and the UK showed that the natural course of CHD resulted in death at the end of the first year of life in more than $70 \%$ of cases. In North America, CHDs are the cause of death of 37\% of infants and in Western Europe, 45\% [5,6]. In the Russian Federation, the birth rate of children with CHDs is from 3.2 to 8.0 per 1,000 live births and tends to rise [5]. According to

*Corresponding author: Tatiana E. Burtseva, PhD, ScD. Deputy Director of the Yakutsk Research Center for Complex Medical Problems, Yakutsk, Sakha Republic, Russia E-mail: bourtsevat@, rambler.ru the Russian State Statistics Committee (2013), the SR(Y) has a population of 955,580 people. The population of Yakutsk is 311,900 people. In the $\mathrm{SR}(\mathrm{Y})$, in the structure of infant mortality for a number of years, CDFs have takeen second place after the "diseases specific to the neonatal period." In 2012 compared to 2010 , in connection with the transition to neonatal care of infants with extremely low birth weight and registration of births from 22 weeks of pregnancy (according to WHO criteria), there was an increase in the infant mortality rate (IMR) of about 1.4 times (9.9 per 1,000 live births) and in the perinatal mortality rate (PMR) of about 1.6 times (13.7 per 1,000 live births and stillborn). In the structure of IMR, the proportion of CDF increased by about 1.5 times. The multiple malformations (33.9\%) and malformation of heart and central nervous system $(21.4 \%)$ retain a leading position in the structure of all congenital malformations. Congenital malformations, of which $48.3 \%$ are anomalies of the circulatory system, are the main causes of disability in children, according to the Sakha Ministry of Health (2012). Thus, a significant contribution of CHDs to the formation of perinatal and infant mortality, and disability of children, as well as insufficient data on the spread, frequency and structure 
of CHD in the SR(Y), served as the cause for this study, which was performed for the first time.

The aim of this study was to analyze the structure of CHDs and great vessels in the newborns in the SR(Y) according to the data of the Perinatal Center of the SR(Y) in periods from 2002 to 2004 and from 2011 to 2013.

\section{Material and Methods}

A retrospective study of newly diagnosed cases of CHDs among newborns was conducted on the basis of the Perinatal Center of the SR(Y) at the department of neonatal pathology, at the department of neonatal care for premature infants, and at the department of infectious diseases of newborn infants. The study included all cases of CHDs in infants born alive. The study was divided into two time periods: Period A (from 2002 to 2002) and Period B (from 2011 to 2013). Period A was considered as a control group. CHD were recorded according to ICD-10: Chapter XVII "Congenital malformations, deformations and chromosomal abnormalities", subparagraph "Congenital malformations of the circulatory system " (Q20-Q28). Primary documentation included hospital journals and statistical cards of the inpatients. The clinical diagnosis of CHD was confirmed by Doppler echocardiography of the heart and blood vessels, ECG, X-ray, angiographic study, and CT angiography. Incidence rate was calculated per 1,000 live births. Written informed consent was obtained from the child's parents. Statistical analysis was performed using statistical software "Statistics Calculator", https://www.statpac.com/ statistics-calculator/percents.htm). $P$ values of $<0.05$ were considered statistically significant.

\section{Results and Discussion}

According to case records, diagnosis of CHDs among newborns was registered in 186 cases for Period A and in 899 cases for Period B. A comparative analysis of the prevalence of CHD detection and the structure of clinical entities of CHDs among liveborn infants in Period A $(42,827$ liveborn infants and 186 cases of CHDs) and Period B (50,104 liveborn infants and 899 cases of CHDs) was performed. The results of the study are presented in Table 1. According to our data, the prevalence of CHDs among newborns in Period A was 4.34 per 1,000 live births, which corresponded to the average CHD frequency in Russia [1]. The prevalence of CHDs among newborns in Period B was 17.9 per 1,000 live births, which is significantly higher than in Period A $(P=0.0000)$. The increase in the prevalence of CHDs could be due to many factors, including improvement in the quality of diagnosis in 2011-2013.

All cases of CHDs were divided into three groups: 1) septal defects: atrial septal defect (ASD), ventricular septal defect (VSD) in combination with patent ductus arteriosus (PDA), and pulmonary valve stenosis (PVS); 2) complex CHDs: pulmonary atresia (PA), tetralogy of Fallot (ToF), atrioventricular septal defect (AVSD), total anomalous pulmonary venous connection (TAPVC), transposition of the great vessels (TGV), pulmonary stenosis, Ebstein's anomaly, tricuspid atresia, single ventricle, double outlet right ventricle (DORV), truncus arteriosus, and mitral valve atresia (MVA); 3) other CHDs: patent ductus arteriosus (PDA), coarctation of the aorta (CoA), PVS, partial anomalous pulmonary venous connection (PAPVC), tricuspid valve dysplasia, and coronary artery anomalies (CAAs). We analyzed the prevalence and frequency of malformations in view of the groups and the periods of the study (Table 1).

The results showed a statistically significant increase in the prevalence of all CHDs in Period B compared to Period A $(P=0.0000)$. The prevalence of septal defects increased from $3.08(\mathrm{n}=42.827$ newborns $)$ to $15.55(\mathrm{n}=50.104$ newborns $)$, of complex CHDs from 0.54 ( $\mathrm{n}=42.827$ newborns) to 0.92 $(\mathrm{n}=50.104$ newborns), and of other CHDs from $0.61(\mathrm{n}=50.104$ newborns) to 1.48 ( $\mathrm{n}=50.104$ newborns). The frequency of septal defects increased from $73.66 \%$ ( $\mathrm{n}=186$ CHDs) to $86.65 \%$ ( $\mathrm{n}=899$ CHDs), and the frequency of the complex CHDs decreased from $12.37 \%$ ( $\mathrm{n}=186$ CHDs) to $4.67 \%$ $(\mathrm{n}=899$ CHDs $)$, in comparison with Period A $(P=0.0001)$. We also noted a decrease in frequency of other CHDs from $13.97 \%$ $(\mathrm{n}=186$ CHDs) to $8.68 \%(\mathrm{n}=899 \mathrm{CHDs})$ in the structure of CHDs $(P=0.0259)$. Thus, we concluded that the overall growth of the incidence of CHDs among newborns in period $\mathrm{B}$ was due to an increase in the prevalence and frequency of septal defects.

Table 1.

The structure of CHDs among newborns

\begin{tabular}{|c|c|c|c|c|c|c|c|c|}
\hline \multirow{2}{*}{$\begin{array}{l}\text { CHDs } \\
\text { (ICD-10) }\end{array}$} & \multicolumn{3}{|c|}{ Period A (2002-2004) } & \multicolumn{3}{|c|}{ Period B (2011-2013) } & \multicolumn{2}{|c|}{$P$} \\
\hline & $\begin{array}{l}\text { Abs. number } \\
\text { of CHDs }\end{array}$ & 1) & 2) & $\begin{array}{c}\text { Abs. number } \\
\text { of CHDs }\end{array}$ & 3) & 4) & 1) vs. 3) & 2) vs. 4) \\
\hline $\begin{array}{l}\text { Group of complex } \\
\text { CHDs }\end{array}$ & 23 & 0.54 & 12.37 & 46 & 0.92 & 4.67 & $P=0.0000$ & $P=0.0001$ \\
\hline Total & 186 & 4.34 & & 899 & 17.94 & & $P=0.0000$ & \\
\hline
\end{tabular}

1)The prevalence of CHDs per 1,000 live births $\pm 0.01, n=42,827$ newborns. 2) The frequency of the individual forms of CHDs ( $\% \pm 0.01), n=186$ CHDs. 3) The prevalence of CHDs per 1,000 live births $\pm 0.01, n=50,104$ newborns. 4) The frequency of the individual forms of CHDs ( $\% \pm 0.01, n=899$ CHDs. 
Table 2.

Nosological forms of CHDs for 2002-2004 and 2011-2013

\begin{tabular}{|c|c|c|c|c|c|c|c|c|}
\hline \multirow{2}{*}{$\begin{array}{c}\text { CHD } \\
(\mathrm{ICD}-10)\end{array}$} & \multicolumn{3}{|c|}{ Period A (2002-2004) } & \multicolumn{3}{|c|}{ Period B (2011-2013) } & \multicolumn{2}{|c|}{$P$} \\
\hline & $\begin{array}{c}\text { Abs. } \\
\text { number of } \\
\text { CHDs }\end{array}$ & 1) & 2) & $\begin{array}{l}\text { Abs. } \\
\text { number of } \\
\text { CHDs }\end{array}$ & 3) & 4) & 1) vs. 3) & 2) vs. 4) \\
\hline $\begin{array}{l}\text { Q21.0-21.1 } \\
\text { VSD, ASD, } \\
\text { VSD+PDA, PVS }\end{array}$ & 137 & 3.08 & 73.66 & 779 & 15.55 & 86.65 & $P=0.0000$ & $P=0.0000$ \\
\hline $\begin{array}{l}\text { Q25.0 } \\
\text { PDA }\end{array}$ & 8 & 1.19 & 4.30 & 51 & 1.02 & 5.67 & $P=0.01$ & $P=0.45$ \\
\hline $\begin{array}{l}\text { Q25.1 } \\
\text { CoA }\end{array}$ & 0 & 0 & 0 & 21 & 0.42 & 2.34 & $P=0.0000$ & $P=0.04$ \\
\hline \begin{tabular}{|l|} 
Q22.1 \\
PVS
\end{tabular} & 12 & 0.28 & 6.45 & 0 & 0 & 0 & $P=0.0000$ & $P=0.0000$ \\
\hline $\begin{array}{l}\mathrm{Q} 22.0 \\
\mathrm{PA}\end{array}$ & 2 & 0.05 & 1.08 & 7 & 0.14 & 0.78 & $P=0.0000$ & $P=0.68$ \\
\hline $\begin{array}{l}\text { Q21.3 } \\
\text { ToF }\end{array}$ & 4 & 0.09 & 2.15 & 10 & 0.20 & 1.11 & $P=0.0000$ & $P=0.25$ \\
\hline $\begin{array}{l}\text { Q21.0 } \\
\text { AVSD } \\
\end{array}$ & 1 & 0.02 & 0.54 & 10 & 0.20 & 1.11 & $P=0.0000$ & $P=0.48$ \\
\hline $\begin{array}{l}\text { Q26.2-26.3 } \\
\text { TAPVC }\end{array}$ & 1 & 0.02 & 0.54 & 3 & 0.06 & 0.33 & $P=0.0029$ & $P=0.67$ \\
\hline $\begin{array}{l}\text { Q26.3 } \\
\text { PAPVC }\end{array}$ & 5 & 0.12 & 2.69 & 1 & 0.02 & 0.11 & $P=0.0000$ & $P=0.0000$ \\
\hline \begin{tabular}{|l|} 
Q25. \\
Pulmonary stenosis
\end{tabular} & 4 & 0.09 & 2.15 & 4 & 0.08 & 0.45 & $P=0.60$ & $P=0.01$ \\
\hline $\begin{array}{l}\text { Q20.3 } \\
\text { TGV } \\
\end{array}$ & 2 & 0.05 & 1.08 & 4 & 0.06 & 0.45 & $P=0.08$ & $P=0.28$ \\
\hline $\begin{array}{l}\text { Q20.1 } \\
\text { DORV }\end{array}$ & 1 & 0.02 & 0.54 & 2 & 0.04 & 0.22 & $P=0.08$ & $P=0.45$ \\
\hline $\begin{array}{l}\text { Q20.4 } \\
\text { Single ventricle }\end{array}$ & 0 & 0 & 0 & 1 & 0.02 & 0.11 & $P=0.0035$ & $P=0.65$ \\
\hline \begin{tabular}{|l} 
Q22.5 \\
Ebstein's anomaly
\end{tabular} & 1 & 0.02 & 0.54 & 4 & 0.06 & 0.45 & $P=0.0001$ & $P=0.85$ \\
\hline \begin{tabular}{|l|} 
Q22.8 \\
Tricuspid valve \\
dysplasia
\end{tabular} & 0 & 0 & 0 & 1 & 0.02 & 0.11 & $P=0.0035$ & $P=0.65$ \\
\hline $\begin{array}{l}\text { Q22.6 } \\
\text { Tricuspid atresia }\end{array}$ & 1 & 0.02 & 0.54 & 1 & 0.02 & 0.11 & $P=1.00$ & $P=0.21$ \\
\hline $\begin{array}{l}\text { Q20.0 } \\
\text { Truncus arteriosus }\end{array}$ & 2 & 0.05 & 1.08 & 0 & 0 & 0 & $P=0.0000$ & $P=0.0019$ \\
\hline $\begin{array}{l}\text { Q23.4 } \\
\text { MVA }\end{array}$ & 4 & 0.09 & 2.15 & 0 & 0 & 0 & $P=0.0000$ & $P=0.0000$ \\
\hline $\begin{array}{l}\text { Q24.5 } \\
\text { CAAs }\end{array}$ & 1 & 0.02 & 0.54 & 0 & 0 & 0 & $P=0.0016$ & $P=0.03$ \\
\hline Total & 186 & 4.34 & & 899 & 17.94 & & $P=0.0000$ & \\
\hline
\end{tabular}

Note: See Table 1.

We analyzed the structure of CHDs according to the nosological forms (Table 2). In Period B, there was a statistically significant increase in the prevalence and frequency of septal defects (ASD, VSD combined with
PDA and PVS) from 0.32 ( $\mathrm{n}=42.827$ liveborn infants) to 1.55 (50.104 liveborn infants) $(P=0.0000)$ and from $73.66 \%(\mathrm{n}=186$ CHDs) to $86.65 \%(\mathrm{n}=899$ CHDs) ( $\mathrm{p}=0.0000)$, respectively, and the prevalence and frequency of PAPVC decreased from 
0.012 ( $\mathrm{n}=42.827$ liveborn infants $)$ to $0.002(\mathrm{n}=50.104$ liveborn infants) $(P=0.06)$ and from $2.69(\mathrm{n}=186 \mathrm{CHDs})$ to $0.11 \%$ $(\mathrm{n}=899$ CHDs $)(P=0.0000)$, respectively. There was a lack of PVS, arteriosus, and MVA in Period B. Such abnormalities as single ventricle, hypoplastic right heart syndrome, tricuspid valve dysplasia, and CAAs were detected in a few cases in both Periods A and B. Among malformations of the great vessels, CoA was not identified in Period A, while in Period B, 21 cases of CoA were identified with the prevalence of $0.42(n=50.104$ liveborn infants) and frequency of $2.34 \%$ ( $n=899$ CHDs), which may be explained by the improvement in the quality of diagnosis, in particular, the use of cardiac catheterization with $\mathrm{X}$-ray images. It was noted an increase in the prevalence of PA from 0.05 to $0.14(P=0.0000)$, ToF from 0.09 to 0.20 $(\mathrm{p}=0.0000)$, and AVSD from 0.02 to $0.20(P=0.0000)$ without statistically significant change in the share of particular defect in the structure of all CHDs in Period B.

\section{Conclusions}

- Our study revealed a statistically significant increase of the newly diagnosed CHDs among newborns: 17.9 in Period $\mathrm{B}$ versus $4.34(P=0.0000)$ in Period A. The increase in the prevalence of CHDs could be due to many factors, including improvement in the quality of diagnosis in 2011-2013.

- The overall increase in the prevalence and frequency of CHDs among newborns in the Period B was due to an increase in the prevalence and frequency of septal defects.

- The identified 21 cases of CoA with the prevalence of 0.42 (liveborn infants) and frequency of $2.34 \%$ (CHDs) in Period B may be explained by the improvement in the quality of diagnosis, in particular, the use of cardiac catheterization with $\mathrm{x}$-ray images.

- The prevalence of PA, ToF, and AVSD increased without a statistically significant change in the share of particular malformation in the structure of all CHDs in Period B.

- The prevalence and frequency of PAPVC decreased in the structure of all CHDs in Period B.

\section{Competing interests}

The authors declare that they have no competing interests.

\section{References}

1. Mutafian OA. Malformations and minor heart abnormalities in children and adolescents. SPb.: MAPS; 2005. [in Russian].

2. Bogantsev S.V Analysis of the structure of congenital heart defects in children. Omsk Nauch Vest 2006; 3:196-200. [in Russian].

3. Magomedova Sh M. Epidemiology of congenital heart defects in children in different climatic zones of the Republic of Dagestan. Abstract of PhD Thesis. Makhachkala; 2006. [in Russian].

4. Zeminskaya DI, Balaeva LS. Child disability. M .: Med., 2001. [in Russian].

5. Liapin VA. Socially significant pathology of the child population of the industrial center of Western Siberia. SiberiaEast 2005; 3:9-11. [in Russian].

6. Rosano A, Botto LD, Botting B, Mastroiacovo P. Infant mortality and congenital anomalies from 1950 to 1994: an international perspective. J Epidemiol. Community Health 2000; 54(9):660-6. 